\title{
Morphology of the minute larva of Ptinella tenella, with special reference to effects of miniaturisation and the systematic position of Ptiliidae (Coleoptera: Staphylinoidea)
}

\author{
Vasily V. Grebennikov ${ }^{\mathrm{a}, \mathrm{b}, *}$, Rolf G. Beutel ${ }^{\mathrm{c}}$ \\ ${ }^{a}$ Department of Zoology and Entomology, Faculty of Natural and Agricultural Sciences, University of Pretoria, Pretoria 0002, South Africa \\ ${ }^{\mathrm{b}}$ Biodiversity Program, International Centre of Insect Physiology and Ecology, Nairobi, Kenya \\ ${ }^{\mathrm{c}}$ Institut für Spezielle Zoologie und Evolutionbiologie, FSU Jena, Erbertstraße 1, D-07743 Jena, Germany
}

Accepted 27 May 2002

\begin{abstract}
External and internal features of minute reared ex ovo larvae of Ptinella tenella Erichson with the head widths ranging from 108 to $138 \mu \mathrm{m}$ are described. In total 139 setae (trichoid sensilla), 18 pores (non-trichoid sensilla), and 60 muscles were identified. The complexity of the chaetotaxy, the musculature of the head, the tentorium, and the digestive tract are not affected by the extremely small size of the larvae. Specific features, which may have resulted from miniaturisation are the elongate shape of the brain reaching the mesothorax posteriorly, the reduced condition of the thoracic sclerites and endosternites, the simplified musculature of the thorax and abdomen, and the loss of the abdominal spiracles. The monophyly of Ptiliidae is supported by the absence of head sutures, the presence of a setiferous protuberance close to the mandibular base, and the absence of a lacinia. Absence of abdominal spiracles and complete absence of eyes suggest the monophyly of a ptiliid subgroup which does not comprise Nossidium. Presence of a fimbriate galea is shared by larvae of Agyrtidae, Leiodidae, Ptiliidae, and Hydraenidae. The presence of a complex apical appendage on the distal maxillary palpomere and of hooks on abdominal segment X are possible synapomorphies of Ptiliidae and Hydraenidae. A description of the rearing procedure is provided and comments on feeding habits are made. (C) 2002 Elsevier Science Ltd. All rights reserved.
\end{abstract}

Keywords: Ptiliidae; Larvae; Anatomy; Chaetotaxy; Miniaturisation; Phylogeny

\section{Introduction}

Henry Dybas, the late world authority on ptiliids, wrote in 1976 that "there are about 62 genera and about 400 nominal species of Ptiliidae described. Judging by the extensive collections of the family in the Field Museum, only a small part of the species have been named - certainly less than 10 percent." The taxonomic neglect of the minute ptiliid beetles is also highlighted by the fact that a new genus of Nanosellini was recently discovered in Sweden, which is the first record for the tribe in Europe (Sörensson, 1997). Another example is the paper of Hall (1999), which nearly doubles the number of known nanoselline genera.

\footnotetext{
* Corresponding author. Address: Department of Zoology and Entomology, Faculty of Natural and Agricultural Sciences, University of Pretoria, Pretoria 0002, South Africa. Tel.: + 27-12-4204618; fax: + 27-123625242 .

E-mail address: v_grebennikov@mail.ru (V.V. Grebennikov).
}

Apart from earlier accounts that are only of historical interest, very few larvae of Ptiliidae have been described in the first half of the 20th century (Böving and Craighead, 1931: Nossidium; Hinton, 1941: Acrotrichis; Paulian, 1941: Acrotrichis, Ptinella, Mycophagus, Cylindrosella). However, there are a number of inconsistencies and misinterpretations in these few accounts, as might be expected with extremely small larvae (Dybas, 1976). Larvae of Nossidium americanum Motschulsky, Nossidium sp., Pteryx sp., Ptinella sp., Actidium sp., Nanosella sp., Throscoptilium duryi Barber, Actinopteryx fucicola Allibert, Acrotrichis sp., and Nephanes titan Newman were described by Dybas (1976), to date the most comprehensive treatment of ptiliid larvae. More recent descriptions or illustrations were provided by Costa et al. (1988), Hall (1999) and Kilian and Burakowski (2000), and phylogenetically relevant information concerning ptiliid and other staphyliniform larvae 


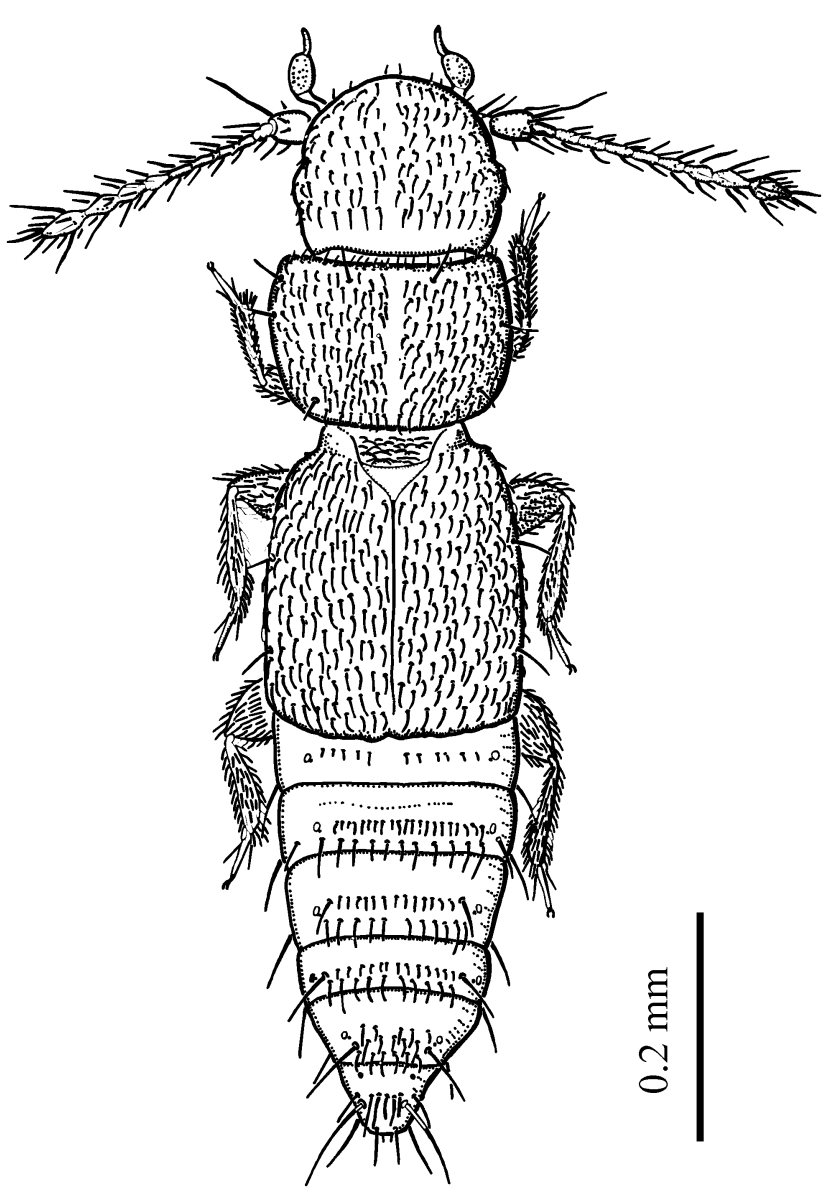

Fig. 1. P. tenella Erichson, 1845, adult, dorsal view.

were presented by Hansen (1997). However, chaetotaxy remained understudied and internal features completely unknown.

One major purpose of this paper is to give a first detailed account of internal and external structures of larvae of Ptiliidae. The larva of Ptinella is the smallest beetle larva ever described in detail. Another main topic, which is strongly suggested by the extremely small size of ptiliids, is the possible effect of the miniaturisation. This question was already discussed in detail for larvae of Myxophaga by Beutel and Haas (1998). Information on rearing procedures is provided and some comments are made on the mouthparts and the feeding habits. Finally, the morphological findings are evaluated with respect to the phylogeny and systematic position of Ptiliidae.

\section{Material and methods}

For this work about 60 larvae of Ptinella tenella Erichson were reared ex ovo from adults (Fig. 1) collected in April 2000 from under the bark of a freshly dead deciduous tree (species undetermined) in the 'Sanatory na Kamenke' park, Rostov-on-Don, southern Russia. Based primarily on spermathecan characters this species has been tentatively identified as $P$. tenella by A.F. Newton; later this ID had been confirmed by Mikael Sörensson. Beetles were kept in two Petri dishes, $100 \mathrm{~mm}$ in diameter, each containing about 20-30 individuals. Some strips of the bark from the same tree were provided as substrate. Prior to this, the strips of bark were kept for 5 min submerged in boiling water to prevent possible contamination with other eggs (Grebennikov, 2001). The Petri dishes were kept indoors at room temperature in a half-closed aquarium with relatively high humidity and protected from direct sunlight.

Unidentified fungi grew on the pieces of bark in both Petri dishes. It is likely that larvae were using the spores of these fungi to feed on. No other food items were added. The first four eggs were separated and transferred to other Petri dishes and treated under similar conditions. These eggs perished shortly thereafter. All successfully bred larvae, pupae and adults of a new generation were collected from the same Petri dishes, where they co-existed with the collected beetles. All life stages were preserved in $70 \%$ ethanol.

Four adult beetles and about 20 larvae representing the greatest size variety were mounted with Euparal on two microscope slides and used for study and description of external morphological characters. Two additional larvae were imbedded in Historesin, cut at $3 \mu \mathrm{m}$ with a Microm HM 360 rotation microtome (cross-sections and longitudinal sections), stained with methylene-blue and acid fuchsine and also mounted with Euparal medium on microscope slides. All slides and the majority of the ethanol material are kept in the first author's collection. Some adults, larvae and all pupae were deposited in the collection of the Field Museum of Natural History, Chicago, USA. Two adults were deposited in Mikael Sörensson collection, Lund, Sweden. Two adults and ten larvae are deposited in Australian National Insect Collection, Canberra, Australia and two adults and five larvae in Gene Hall collection, Boulder, USA.

SEM micrographs were prepared at the Max-PlanckInstitut für Entwicklungsbiologie Tübingen with a Hitachi S-800 scanning electronic microscope. The pictures were used as additional source of information, but were unsuitable for publication due to contamination of the larvae.

Morphological terms used in this work are those explained by Lawrence (1991) (147-177) with the exception that in polyphagan larvae 'tarsungulus' is named 'claw' and 'tibia' is named 'tibiatarsus' (Lawrence, personal communication). Kéler's (1963) nomenclature is used for muscles of the head and abdomen and Larsén's (1966) nomenclature for thoracic muscles. When possible, Speyer's (1922) designation for muscles was added; in the description Speyer's (1922) nomenclature follows the Latin name of the muscle and starts with 'MI'. Letters ' $\mathrm{O}$ ' and ' $\mathrm{I}$ ' following names of muscles mean 'origin' and 'insertion', respectively. Being aware of different chaetotaxy systems proposed for some beetle larvae (Carabidae by Bousquet 
and Goulet (1984); aleocharine Staphylinidae by Ashe and Watrous (1984); Histeridae by Kovarik and Passoa (1993)), we experienced difficulties in applying them to Ptinella larvae. Consequently, we used independent numeration of the sensilla solely to designate them for the present paper. By doing so, we do not propose a chaetotaxy system for Ptiliids. Such an attempt would require a more comprehensive study of a wider variety of larvae and is far beyond the scope of this paper.

In our study, we tried to insure the most detailed and precise descriptions of the larvae. However, due to the very small size and complexity of some structures (mainly legs and mouthparts), we had to limit the description at the point beyond which no confident certainty about morphological characters could be achieved. Consequently, we do not consider this description as being absolutely complete.

\section{Results}

Differences between instars. With the material studied we cannot be certain about the precise number of instars, because the measurements of cephalic capsules $(n=6$; see later) do not allow any grouping. Differences in the chaetotaxy of the smallest and the largest larvae suggest that there are at least two larval instars. This is restricted to the increased complexity of the chaetotaxy on the thoracic terga of the larger and presumably advanced instars (Fig. 3; presumed first-instar larvae: Figs. 19 and 20). This condition is usually observed between first- and older-instar larvae of beetles. In the description below we deal with the chaetotaxy of the advanced stage. All differences between instars are indicated at appropriate parts of the description.

General appearance (Fig. 2). Body length between 0.8 and $1.1 \mathrm{~mm}$. Larvae with normally developed legs and 1segmented, articulated short urogomphi. Head and terga slightly darker than whitish, poorly sclerotized body. Integument smooth, without vestiture. Larval body slightly curved ventrally with head slightly declined and not retracted into prothorax. Body segments not retracted into each other. Abdomen elongated and roughly cylindrical.

Head capsule (Figs. 4-7). Head protracted and prognathous. Maximum width at proximal fifth: 108, 117, 124, 129, 133, and $138 \mu \mathrm{m}$. Ecdysial line (= epicranial suture), clypeolabral and frontoclypeal (= epistomal) sutures absent and, consequently, dorsal surface of cranium consists of single sclerite without subdivisions. Anterior part of head (Fig. 8) forms medially projected, ventrally and laterally declined lobe $(=$ labrum) terminated by nasale with two pointed apices. Other tooth-like nasal structures absent. Stemmata and egg-bursters absent. Lateroventral surface proximad of mandibular base and ventrad of antennal fossae with rounded protuberance on each side of cranium bearing long seta 11. Chaetotaxy: With 29 setae (1-29) and two pores (a, b). Internal characters (Figs. 21 and 22): Dorsal endocarinae absent. Mouth frame with heavily sclerotized and markedly developed epistomal ridge forming dorsal part of peristoma. Posterior arms of tentorium form flat and almost vertical structures together with dorsal arms. Dorsal arms attached to frons by fibrillae. Tentorial bridge slightly curved, connecting proximal parts of posterior arms. Anterior arms connected with upper part of dorsal arms.

Labrum (Figs. 4-7 and 14). Completely fused with head capsule, strongly declined (see above). Musculature: M. labroepipharyngalis (M 7): pair of large bundles, O: medially on dorsal wall of labrum, I: anterior epipharynx M 9 (M. frontoepipharyngalis): absent.

Antenna (Figs. 4-9). Consists of three antennomeres; antennomere II longest and narrowed apically. Chaetotaxy: Antennomere I without setae or pores; antennomere II with one large and long sensorium, four setae (30-33) and one pore (c); no additional dome-like sensilla located near base of sensorium; antennomere III with five long setae (34-37, 39) and one long non-trichoid sensillum (38). Musculature: M. tentorioscapalis anterior, posterior, medialis (M 1, 2, 4), $\mathrm{O}$ : base of anterior arm and dorsal wall of head capsule, immediately close to attachment of dorsal arm, I: anteriorly, posterodorsally and posteroventrally on base of antennomere I.

Mandible (Figs. 5-7, 10 and 11). Asymmetrical, without retinaculum or penicillus; with relatively wide base and distinct mola bearing three or four irregular teeth. Dorsal surface of mola without tubercles or asperities. Prostheca ( = lacinia mobilis or lacinia mandibulae) located distad of mola. Mandibular apex with four or five apical teeth. Chaetotaxy (Figs. 6, 7, 10 and 11): Outer edge with two setae of different length (40, 41). Musculature (Figs. 21-23): M 11 (M. craniomandibularis internus): largest muscle of head, O: extensive parts of dorsolateral, lateral and ventrolateral areas of posterior head capsule, I: adductor tendon. M 12 (M. craniomandibularis externus): composed of two subcomponents, M 12a, O: posterolaterally from head capsule, I: abductor tendon. M 12b: almost vertical, O: dorsolaterally from head capsule at level of M. frontopharyngalis posterior, I: abductor tendon.

Maxilla (Figs. 5-7 and 13). Inserted in deep fossa maxillaris. Relatively small cardo and large stipes connected by hinge. Maxillary palp three-segmented with distal palpomere bearing rounded structure $(=$ digitiform sensillum) on lateral surface at its base. Fixed galea (or mala, homology unclear) with fringed apex (Figs. 5, 13); lacinia not identified. Chaetotaxy: Penultimate palpomere with two setae $(47,48)$; stipes with four setae (42-46); cardo with one seta (42). Musculature (Figs. 21-23): M 15 (M. craniocardinalis), $\mathrm{O}$ : ventrolaterally from head capsule, I: laterally on cardinal base. M 17 (M. tentoriocardinalis): almost vertical like following muscle, O: upper part of posterior tentorial arm and dorsal tentorial arm, I: mesally on ventral surface of cardo. M 18 (M. tentoriostipitalis), O: posterior and dorsal tentorial arm, very close to $\mathrm{M} 17$, I: mesally and laterally on ventral surface of stipes. M 19 (M. craniolacinialis), O: laterally from posterior head capsule, 

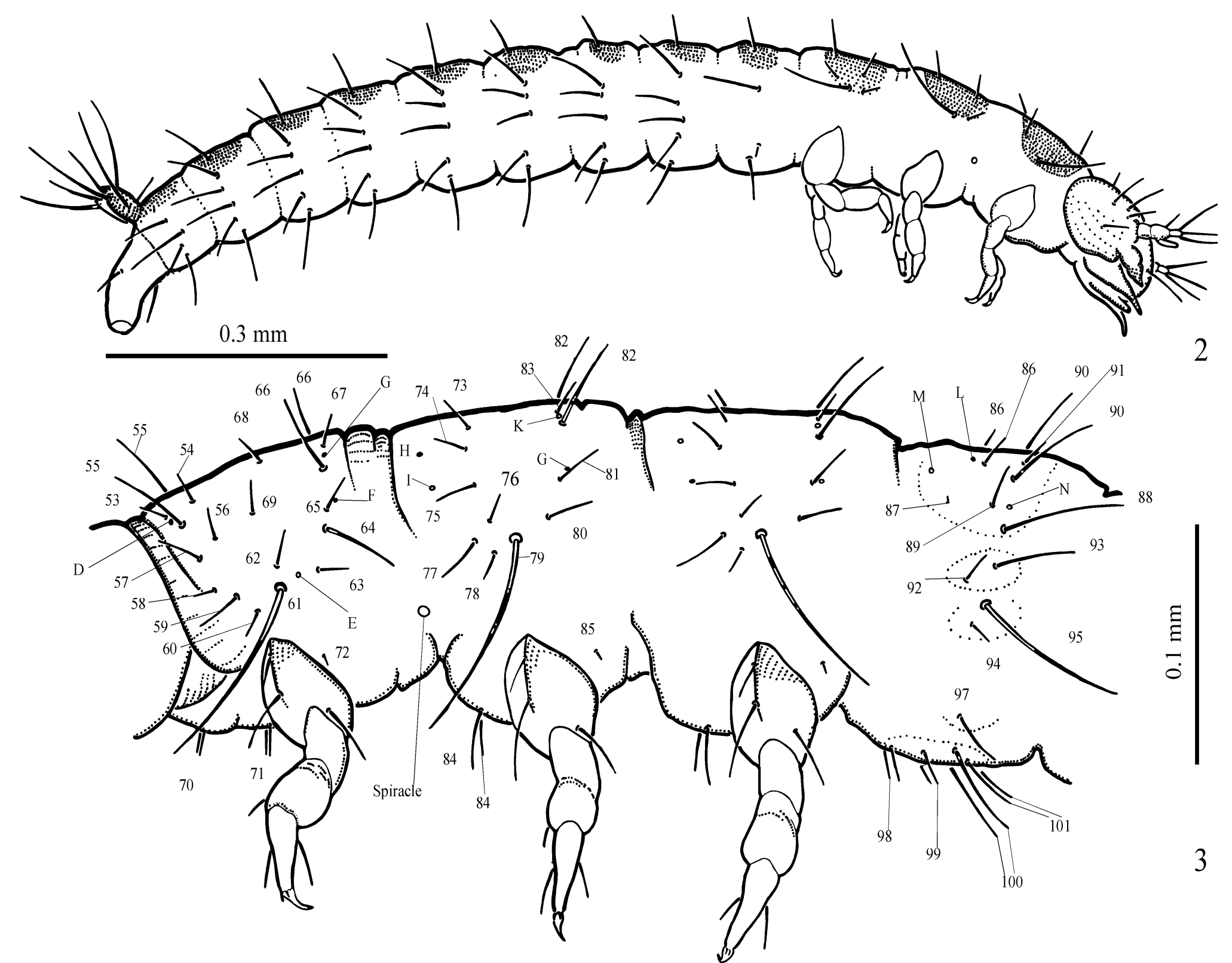


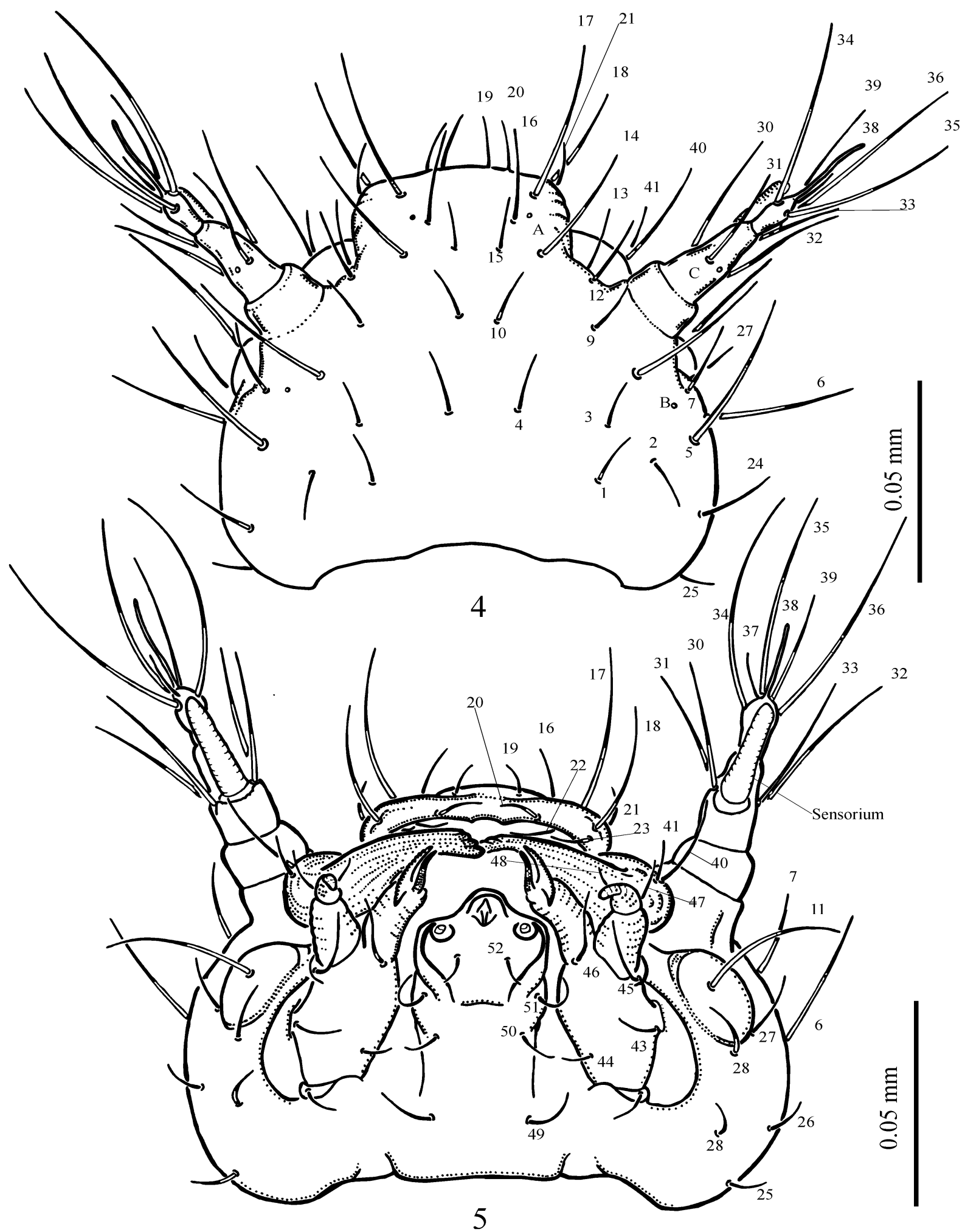

Figs. 4 and 5. Fig. 4: P. tenella Erichson, 1845, larval head. First instar, dorsal view. Fig. 5: P. tenella Erichson, 1845, larval head. Older instar, ventro-frontal view. 


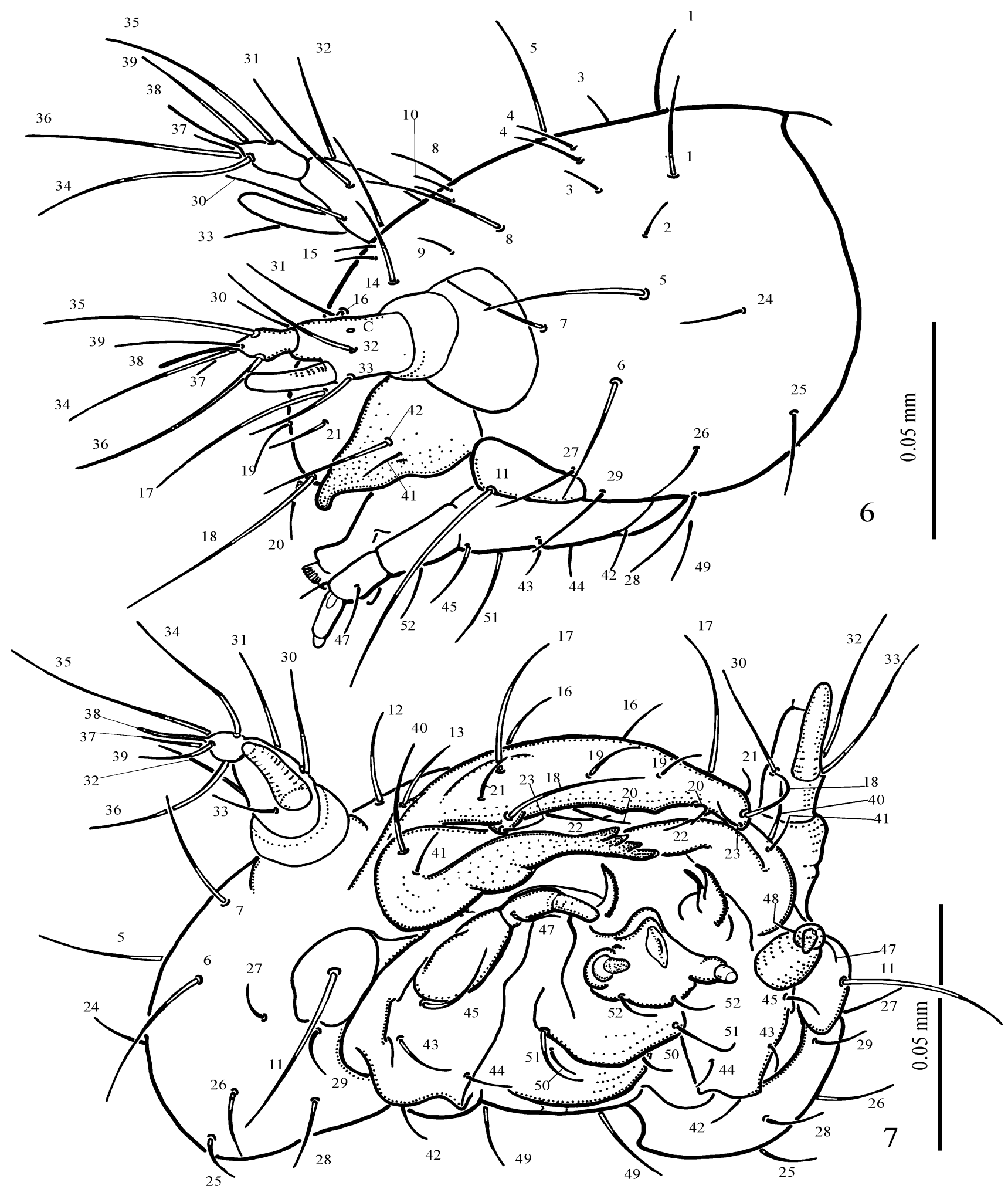

Figs. 6 and 7. Fig. 6: P. tenella Erichson, 1845, larval head, older instar. Left lateral view. Fig. 7: P. tenella Erichson, 1845, larval head, older instar. Right ventro-fronto-lateral view. 


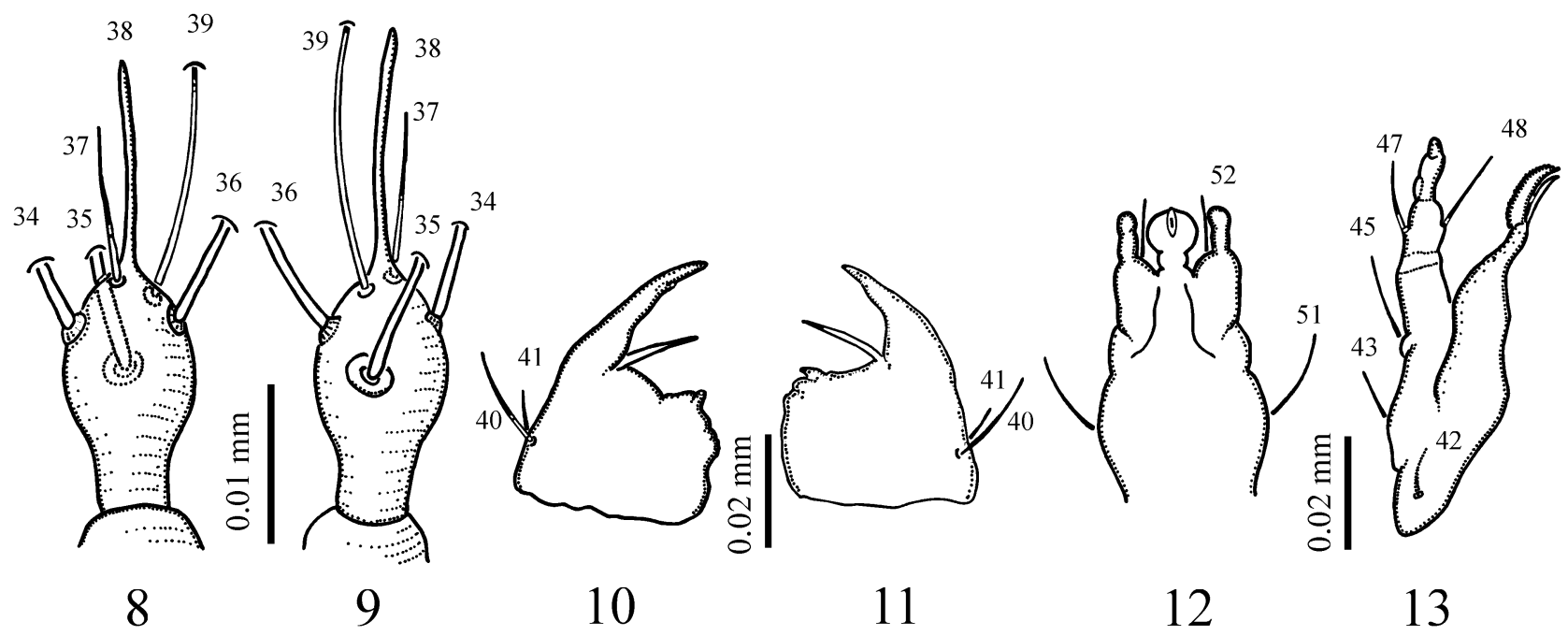

Figs. 8-13. Fig. 8: P. tenella Erichson, 1845, larva, details. Left antennomere III, ventral view. Fig. 9: P. tenella Erichson, 1845, larva, details. Left antennomere III, dorsal view. Fig. 10: P. tenella Erichson, 1845, larva, details. Left mandible, dorsal view. Fig. 11: P. tenella Erichson, 1845, larva, details. Right mandible, dorsal view. Fig. 12: P. tenella Erichson, 1845, larva, details. Labium, dorsal view. Fig. 13: P. tenella Erichson, 1845, larva, details. Left maxilla, dorsal view.

ventrad to M 12a, I: dorsally on base of maxilla. M 22, 23 (Mm. stipitopalpalis externus and internus), O: stipes, I: base of palpomere I.

Labium (Fig. 12). Palp segmentation and borders between mentum, submentum and gula indistinct. Ligula with short sclerotized keel dorsally on rounded apex. Chaetotaxy (Figs. 5 and 7): four setae found on ventral surface of labium and/or gula (homology unclear) (49-52). Musculature (Figs. 21, 23-25): M 28 (M. submentopraementalis), O: posterior submental region, I: ventromesally on hind margin of mentum. M 29 (M. tentoriopraementalis inferior), $\mathrm{O}$ : posterior tentorial arm, I: laterally on hind margin of prementum. M 30 (M. tentoriopraementalis superior), O: posterior tentorial arm, I: not clearly identified, probably dorsolaterally on hind margin of prementum. M 34 (M. praementopalpalis ext.): not identified, probably absent.

Epipharynx (Figs. 21 and 25). Posterior part not fused with hypopharynx laterally, thus closed prepharyngeal tube absent. Musculature (Figs. 21 and 25): M 43 (M. clypeopalatalis): pair of two parallel bundles, O: frontoclypeal region, anterad to anterior component of $\mathrm{M} 41$, I: dorsolaterally on posterior epipharynx.

Hypopharynx (Figs. 21, 24 and 25). With anterior hypopharyngeal surface continuous with dorsal side of prementum. Lateral walls of posterior hypopharynx connected by transverse bar. Hypopharyngeal sclerome not found. Musculature (Figs. 21, 22 and 24): M 41 (M. frontohypopharyngalis): large muscle, composed of two subcomponents: M 41a: fan-shaped, O: frons, laterad and posterad to $\mathrm{M} 45$, I: laterally on posterior edge of epipharynx, and M 41b: strong vertical bundle, O: anterad to $\mathrm{M} 45$, I: anterad to $\mathrm{M}$ 41a, lateral side of posterior hypopharyngeal margin. M 42 (M. tentoriohypopharyngalis): pair of median muscles, O: tentorial bridge, I: medially on hind margin of hypopharynx. Transverse hypopharyngeal muscle absent.

Pharynx (Figs. 21, 22-24 and 26). Moderately wide and approximately quadrangular in cross-section, with indistinct dorsolateral and ventrolateral folds. Musculature (Figs. 21-23): M 45 (M. frontobuccalis anterior), O: anterior part of frontal region, mesad to $\mathrm{M} 41 \mathrm{a}$ and posterior to $\mathrm{M} 41 \mathrm{~b}, \mathrm{I}$ : dorsolaterally on pharynx, immediately posterior to anatomical mouth. M 46 (M. frontobuccalis posterior): two thin parallel bundles, O: frons, posterior to origin of $\mathrm{M} 41 \mathrm{a}, \mathrm{I}$ : dorsolateral on pharynx. M 50 (M. tentoriobuccalis posterior), O: tentorial bridge, I: ventrally on anterior pharynx, ventrad to attachment of $M$. frontobuccalis posterior. M 51 (M. verticopharyngalis): absent. M 52 (M. tentoriopharyngalis): a posterior tentoriopharyngeal muscle with typical origin and insertion could not be identified (it cannot be fully excluded that the muscle designated here as M 50, is in fact M 52, with anteriorly shifted insertion). Ring musculature present.

Cerebrum, suboesophageal ganglion and glands (Fig. 26). Elongate cerebrum almost completely shifted to thorax. Posterior part reaches position of mesothoracic ganglion posteriorly. Suboesophageal ganglion elongate and located in prothorax. Ventral, tube-like glands and glands of antennal insertion area absent.

Prothorax (older instar: Fig. 3; first instar: Fig. 19). Slightly longer than meso- and metathorax, subcylindrical in cross-section. Anterodorsal margin forms distinct collar. Border of slightly sclerotized tergal region indistinct. Lateral and ventral sclerotizations absent. Profurca present but short and inconspicuous. Chaetotaxy: In older-instar larvae with 17 setae on each side of tergum (setae 53-69) and four pores (d-g); in first instar, four setae absent (setae 54, 60, 62, 65) and two pores not identified (e, f). Lateral surface of prothorax with one seta (72); ventral surface with two setae 


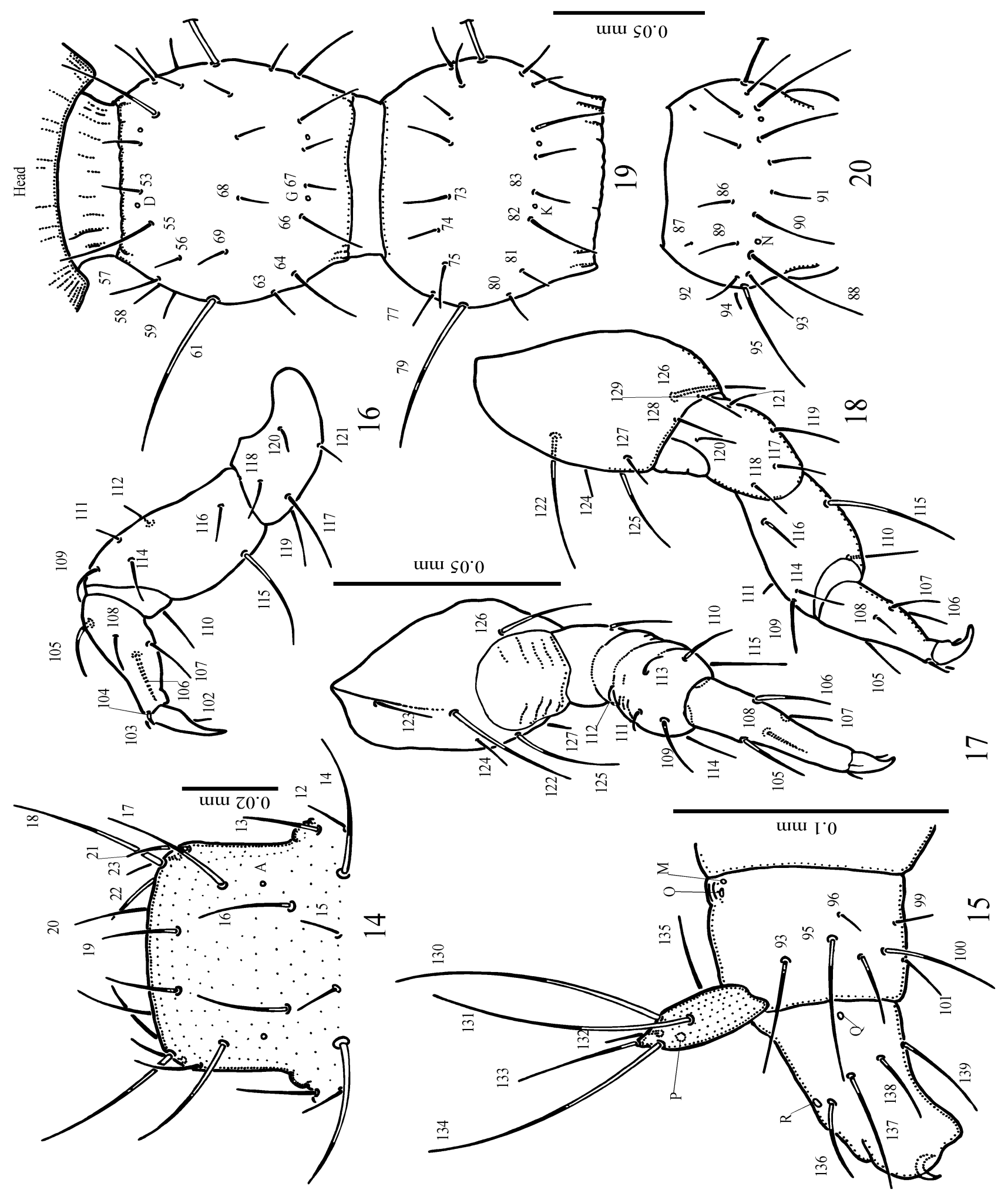




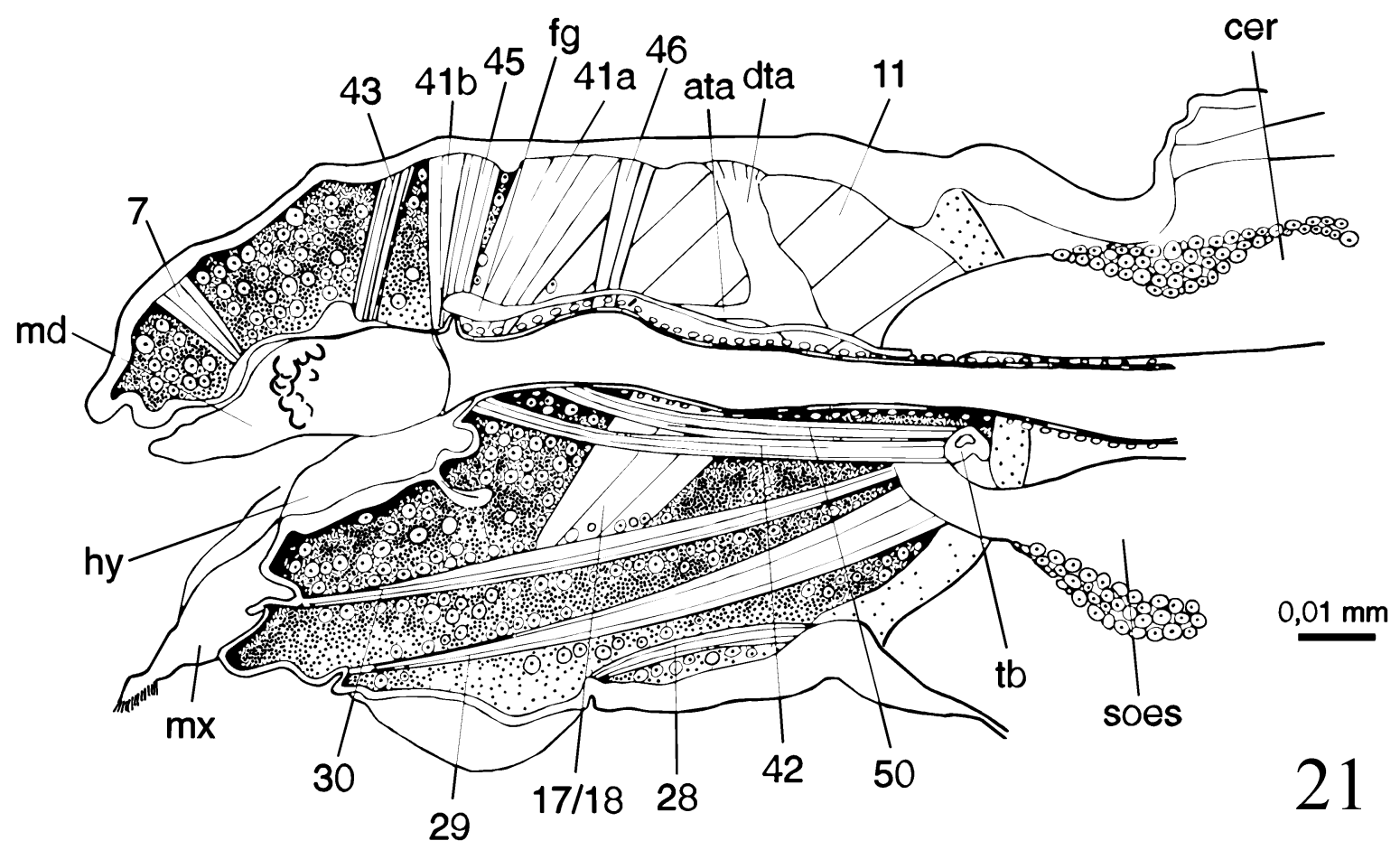

Fig. 21. P. tenella Erichson, 1845, larval head, older instar, sagittal section. Abbreviations: ata—anterior tentorial arms; cer-cerebrum; dta—dorsal tentorial arm; fg—frontal ganglion; hy-hypopharynx; lbr-labrum; md-mandible; soes—suboesophageal ganglion; tb-transverse sclerotized bar; 7-M. labroepipharyngalis $11-\mathrm{M}$. craniomandibularis internus; 17-M. tentoriocardinalis; $18-\mathrm{M}$. tentoriostipitalis; 28-M. submentopraementalis; 29-M. tentoriopraement. inferior; 30-M. tentoriopraement. superior; 41-M. frontohypopharyngalis; 42-M. tentoriohypopharyngalis.; 43-M. clypeopalatalis; 45-M. frontobuccalis anterior; 46-M. frontobuccalis posterior; 50-M. tentoriobuccalis posterior.

(70, 71). Musculature (Figs. 26 and 27): Dorsal muscles: M 1 (M. pronoti primus; $\mathrm{MI}_{2}$, see: Speyer, 1922), O: anterior protergum, I: dorsally on cervical membrane. M 2 (M. pronoti secundus; $\mathrm{MI}_{1}$ ), O: medially on first phragma, I: dorsally on postoccipital ridge. $\mathrm{M} 3$ (M. pronoti tertius; $\mathrm{MI}_{1}$ ), $\mathrm{O}$ : first phragma, laterad to $\mathrm{M} 2$, I: cervical membrane. M 4 (M. pronoti quartus; $\mathrm{MI}_{3 \mathrm{a}, \mathrm{b}}$ ), O: first phragma; I: protergum, laterad to M 1. Ventral muscles: M 5 (M. prosterni primus; $\mathrm{MI}_{4 \mathrm{a}}$ ): short, slender muscle, O: profurca, I: ventrolaterally on postoccipital ridge. M 6 (M. prosterni secundus; $\mathrm{MI}_{4 \mathrm{~b}}$ ): long muscle composed of several parallel bundles, O: fold between pro- and mesosternum, I: posterior margin of posterior tentorial arms. Dorsoventral muscles: M 7 (M. dorsoventralis primus; $\mathrm{MI}_{7 \mathrm{a}}$ ), $\mathrm{O}$ : anterior pronotum, I: ventrolaterally on postoccipital ridge. M 8 (M. dorsoventralis secundus; $\mathrm{MI}_{7 \mathrm{~b}}$ ), O: first phragma, laterad to M 2 and M 3, I: postoccipital ridge, laterad to posterior tentorial arm. M 9 (M. dorsoventralis tertius; absent in Dytiscus; Speyer, 1922), O: anterior notal margin, immediately close to $\mathrm{M} 7$, I: ventrolaterally on postoccipital ridge (this muscle might be a subcomponent of $\mathrm{M} 7$ or vice versa); origin and insertion lie closely together. M 10 (M. dorsoventralis quartus; $\mathrm{MI}_{6}$ ), O: anterior prosternum, I: laterally on postoccipital ridge. M 11 (M. dorsoventralis quintus; $\mathrm{MI}_{11}$ ), O: first phragma, I: area of insertion not clearly identified, probably on posterior margin of prosternum (homology of this muscle is problematic; usually M 11 inserts on the profurca). One muscle with unclear homology originates on the anterior protergum and inserts on the anterior sternum. Lateral muscles: M 12 (M. noto-pleuralis; absent in Speyer, 1922), O: laterally from protergum, laterad to $\mathrm{M}$. noto-coxalis anterior (M 15a), I: propleura, anterad to origin of M 20. M 13 (M. pronotomesepisternalis): not identified, probably absent.

Legs (Figs. 16-18). Chaetotaxy: Claw with one seta ventrally (102); tibiatarsus with six setae (103-108); femur with eight setae (109-116); trochanter with five setae (117-121); coxa with eight setae (122-129). Musculature: M 14 (M. noto-trochantinalis): not identified, probably absent. M 15a (M. noto-coxalis anterior; $\mathrm{MI}_{13 \mathrm{a}, \mathrm{b}}$ ?, Speyer, 1922), O: protergum, laterad to attachment area of M 1 and M 4, I: anterior coxal margin. M 15b (M. noto-coxalis posterior; $\mathrm{MI}_{13 \mathrm{c}-\mathrm{e}}$ ): composed of several bundles, O: posterior protergum, I: posterior coxal margin. M 16, 17 (Mm. episterno/epimerocoxalis): absent. M 18

Figs. 14-20. Fig. 14: P. tenella Erichson, 1845, larva, details. Anterior part of head capsule, dorsal view, older instar. Fig. 15: P. tenella Erichson, 1845, larva, details. Abdominal segments IX (with urogomphi) and X ( = pygopod), right lateral view, older instar. Fig. 16: P. tenella Erichson, 1845, larva, details. Right middle leg (without coxa), frontal view, older instar. Fig. 17: P. tenella Erichson, 1845, larva, details. Left middle leg, lateral view, older instar. Fig. 18: $P$. tenella Erichson, 1845, larva, details. Right hind leg, fronto-medial view, older instar. Fig. 19: P. tenella Erichson, 1845, larva, details. Pro- and mesothorax, dorsal view, first instar. Fig. 20: P. tenella Erichson, 1845, larva, details. Abdominal segment I, dorsal view, first instar. 


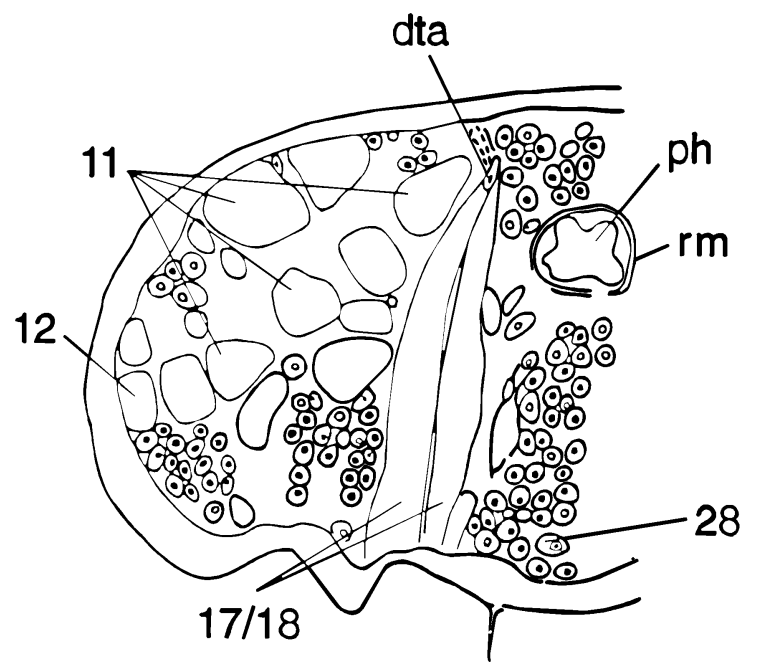

22

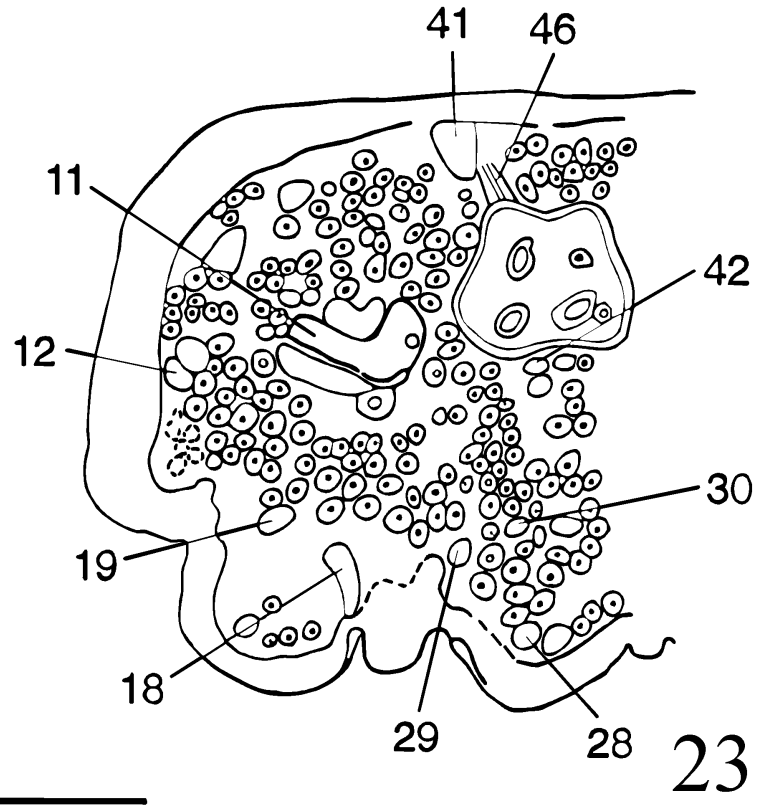

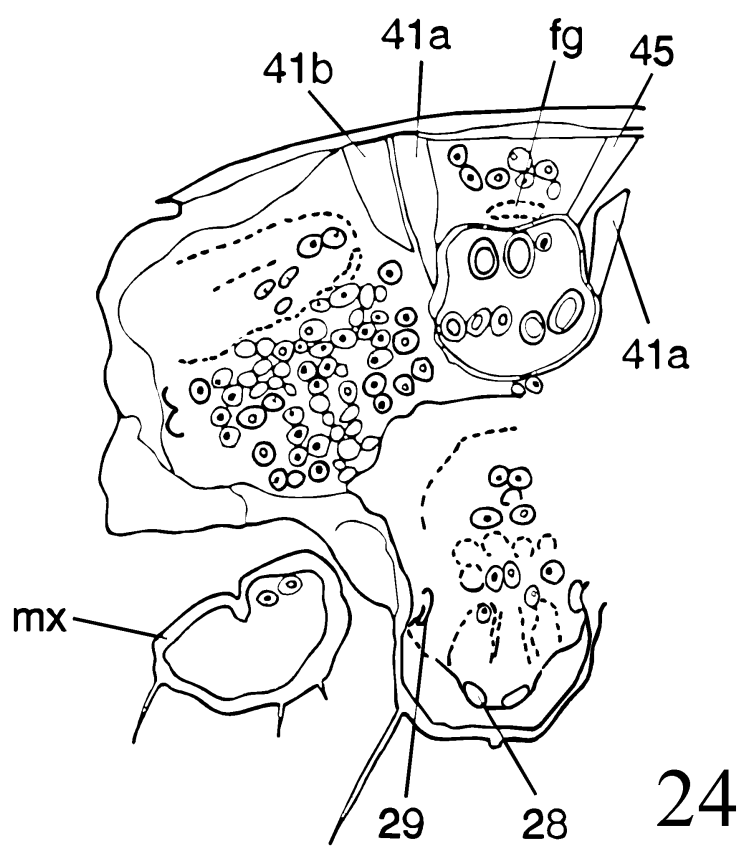

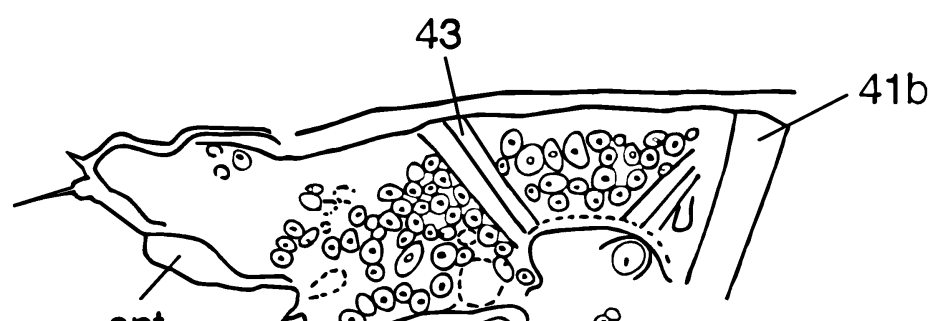

24

ant

$\mathrm{md}$

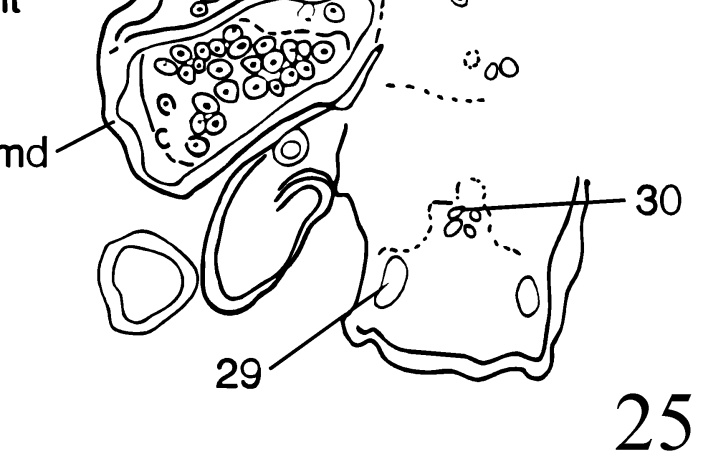

Figs. 22-25. Fig. 22: P. tenella Erichson, 1845, larval head, cross-sections. Posterior pharyngeal region. Fig. 23: P. tenella Erichson, 1845, larval head, crosssections. Anterior pharyngeal region. Fig. 24: P. tenella Erichson, 1845, larval head, cross-sections. Anatomical mouth region. Fig. 25: P. tenella Erichson, 1845, larval head, cross-sections. Posterior epipharyngeal region. Abbreviations: ant-antenna; dta—dorsal tentorial arm; fg-frontal ganglion; mdmandible; mx - maxilla; ph—pharynx; rm—ring muscles; Mm 11-M. craniomandibularis internus; 12—M. craniomandibularis externus; 18—M tentoriostipitalis; $19-$ M. craniolacinialis; $28-$ M. submentopraementalis; $29-$ M. tentoriopraementalis inferior; 30-M. tentoriopraementalis superior; 41M. frontohypopharyngalis; $42-$ M. tentoriohypopharyngalis.; 43-M. clypeopalatalis; 45-M. frontobuccalis anterior; 46-M. frontobuccalis posterior.

(M. sterno coxalis): not identified, probably absent. M 19 (M. furca coxalis; $\mathrm{MI}_{14}$ ): thin muscle, O: profurca, I: laterally on coxal base. Four furca-coxal muscles are present in Dytiscus marginalis Linnaeus, 1758 (see: Speyer, 1922); precise homology is unclear. M 20 (M. pleuratrochanteralis): large muscle, $\mathrm{O}$ : propleura, I: trochanteral tendon. This muscle was not mentioned by Speyer (1922); it is possible that it was erroneously interpreted as coxal muscle (see M 15a,b). M 21 (M. coxotrochanteralis medialis; internal leg muscles not treated by Speyer, 1922), O: coxal wall, I: trochanteral tendon, together with M 20. M 22 (Mm. coxotrochanteralis lateralis), O: coxal wall, I: anteriorly on base of trochanter. Distal leg muscles could not be clearly identified. One muscle originating in coxa or base of trochanter is attached to the base of single claw by a long tendon. Two muscles 

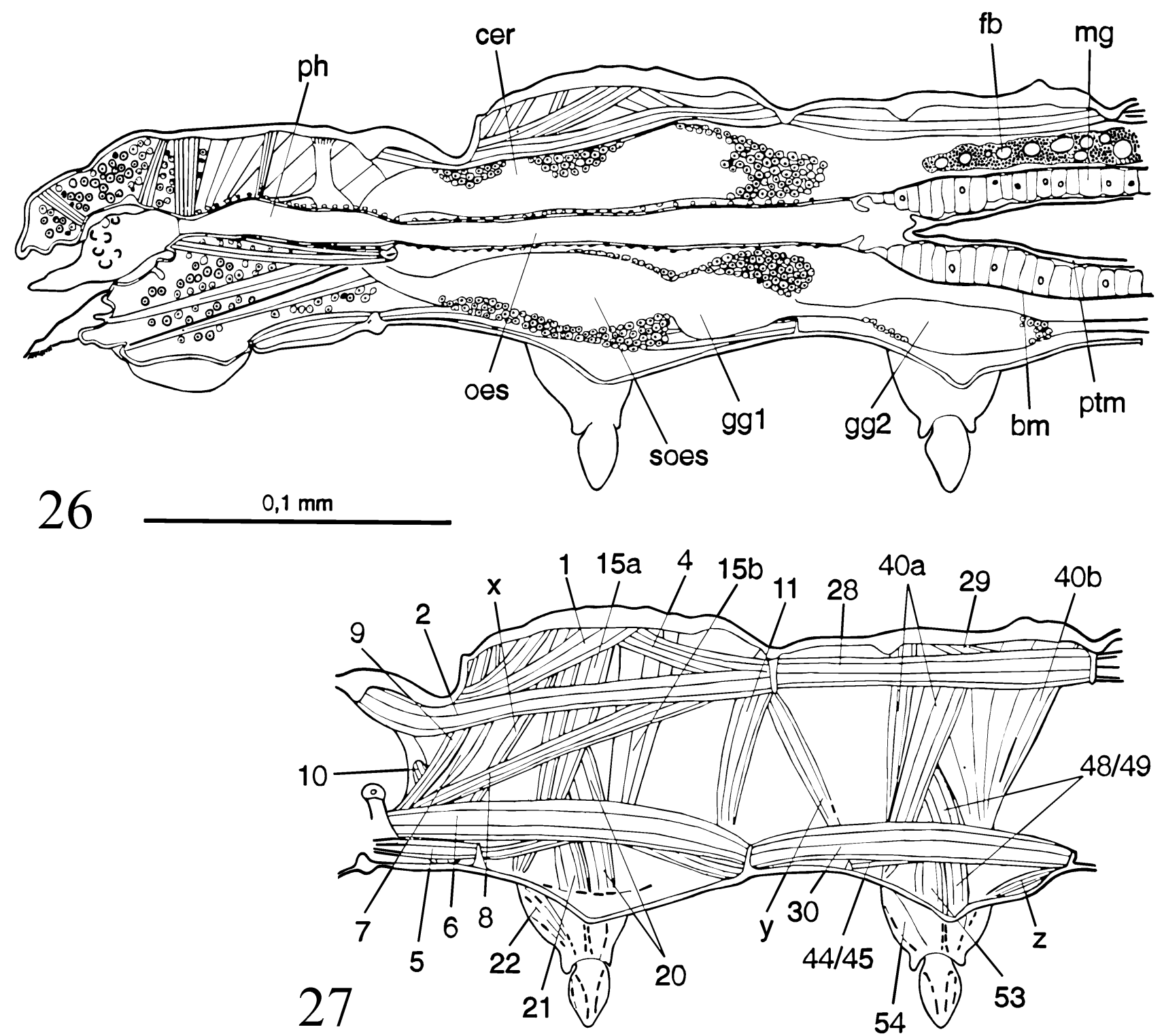

Figs. 26 and 27. Fig. 26: P. tenella Erichson, 1845, older-instar larva, sagittal sections. Head, pro- and mesothorax. Fig. 27: P. tenella Erichson, 1845, olderinstar larva, sagittal sections. Prothorax and mesothorax (brain and digestive tract removed). Abbreviations: bm—basement membrane; cer-brain; fb-fat body; gg1, 2-prothoracic and mesothoracic ganglia, mg-mid-gut; oes-oesophagus; ph—pharynx; ptm-peritrophic membrane; soes-suboesophageal ganglion; $1-$ M. pronoti primus; 2-M. pronoti secundus; $4-\mathrm{M}$. pronoti quartus; $5-\mathrm{M}$. prosterni primus; $6-\mathrm{M}$. prosterni secundus; 7-M. dorsoventralis primus; $8-\mathrm{M}$. dorsoventralis secundus; $9-\mathrm{M}$. dorsoventralis tertius; $10-\mathrm{M}$. dorsoventralis quartus; $11-\mathrm{M}$. dorsoventralis quintus; $15 \mathrm{a}$, b-M. notocoxalis I; 20-M pleura-trochanteralis I; 21, 22-M. coxa-trochanterales I; 28, 29-M. mesonoti primus, secundus; 30-M. mesosterni primus; 44/45-M. furcacoxalis; 48/49-M. episterno- or epimero-trochanteralis; 53, 54-M. coxotrochanterales II.

(probably Mm. depressor and levator tibiae: M 24, 25) originate in the femur and insert on the base of the tibiotarsus.

Mesothorax. Slightly shorter than prothorax, collar region absent, otherwise similar. Legs: similar to pro- and metathoracic legs. Chaetotaxy: Older-instar larvae with 11 setae on each side of tergum (setae 73-83) and four pores $(\mathrm{h}-\mathrm{k})$; in first instar, two setae absent $(76,78)$ and three pores not found $(\mathrm{h}-\mathrm{j})$. Lateral surfaces of with one seta $(85)$; ventral surface with one seta on each side (84). Musculature: Similar to prothoracic except for absence of cervical muscles. M 28 (M. mesonoti primus; $\mathrm{MII}_{1}$ ), O: first phragma, I: second phragma. M 29 (M. mesonoti secundus; $\mathrm{MII}_{3}$ ), O: laterally from mesotergum, I: second phragma. M 30 (mesosterni primus; $\mathrm{MII}_{4}$ ), O: ventral fold between proand mesothorax, I: ventral fold between meso- and metathorax. My: an oblique, dorsoventral muscle, which originates from the first phragma; the precise insertion could not be identified. M 44/45 (M. furca-coxalis anterior or lateralis; $\mathrm{MII}_{14}$ ), O: mesofurca, I: laterally on coxal base. M 48/49 (M. episterno- and M. epimero-coxalis): similar to M 20, O: mesopleura, I: trochanteral tendon. $\mathrm{M} \mathrm{II}_{15}$ (Fig. 27: z); M. 'furcillo'-coxalis mesothoracis, Speyer, 1922; (muscle not listed for adults in Larsén, 1966), O: fold 

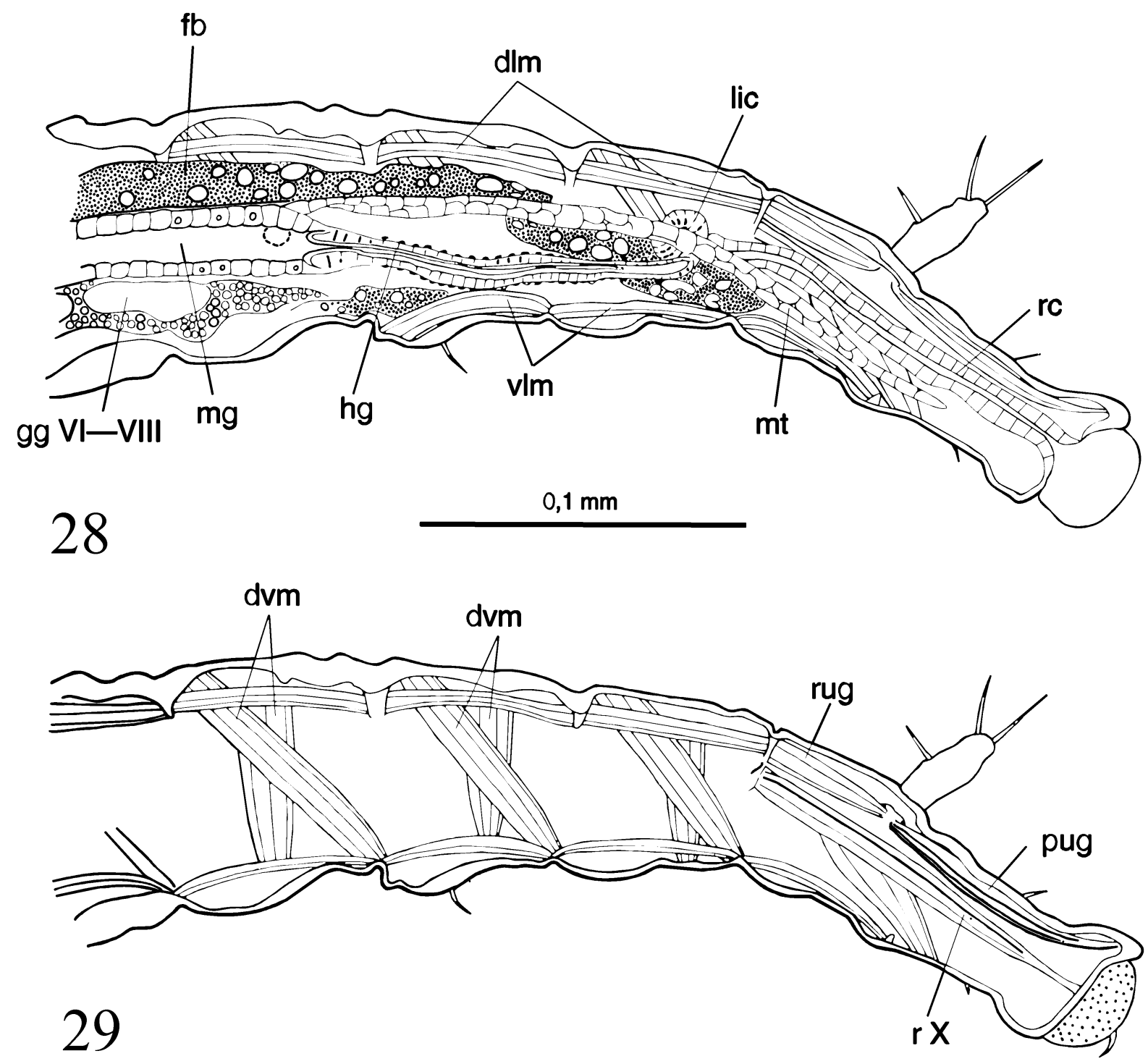

Figs. 28 and 29. Fig. 28: P. tenella Erichson, 1845, older-instar larva, abdominal segments V-X, sagittal sections. Fat body, digestive tract, and ganglia. Fig. 29: P. tenella Erichson, 1845, older-instar larva, abdominal segments V-X, sagittal sections. Musculature. Abbreviations: dlm-dorsal longitudinal muscles; fb—fat body; ggVI-VIII—ganglia VI-VIII; hg—hind-gut; lic-loop of ileocolon; mg—mid-gut; mt—malpighian tubules; rc-rectum; rug-retractor of urogomphus; rX—retractor of segment X; pug—protractor of urogomphus; vlm—ventral longitudinal muscles.

between meso- and metasternum, I: posteriorly on mesocoxa.

Metathorax. Similar to mesothorax, legs similar to proand mesothoracic legs. Chaetotaxy and Musculature: similar to mesothorax.

Abdominal segments I-VIII (Figs. 2, 3, 20, 28 and 29). Segments similar in shape, roughly cylindrical but rounded laterally, slightly decreasing size posteriorly. Chaetotaxy: Older-instar larvae with six setae on each side of tergum (setae 86-91) and three pores (1-n); first instar with all setae present and two pores not found $(1, \mathrm{~m})$. Lateral surface with four setae (92-95); ventral surface with six setae (96101); first abdominal segment lacks seta 96. Musculature (Figs. 28 and 29): Dorsal longitudinal muscles (dlm): M 170, 171 (M. antecostaantecostalis; $=\mathrm{A}_{1}, \mathrm{Mm}$. dorsales abdominis, Speyer, 1922): several parallel bundles, O: anterior phragma, I: posterior phragma. Ventral longitudinal muscles (vlm): M 175, 177 (M. antecostaantecostalis urosterni; $=\mathrm{A}_{3}$, Mm. ventrales abdominis, Speyer, 1922): several parallel bundles, O: ventrally on anterior margin of segment, I: ventrally on posterior margin of segment I. Dorsoventral muscles (dvm): five urotergosternal muscles listed in Kéler (1963) based on the morphology of adults of Orthoptera. The precise homology is unclear. M. urotergosternalis internus $\left(\mathrm{A}_{5 \mathrm{e}}, \mathrm{M}\right.$. dorsoventralis abdominis e, Speyer, 1922), O: anterolaterally on tergum, I: posterolateral margin of sternum. M. urotergosternalis externus ( $\mathrm{A}_{5 \mathrm{~b}}$, M. dorsoventralis abdominis b, Speyer, 1922), O: laterally on tergum, I: laterally on anterior sternum. Abdominal ganglia (Fig. 28): posterior abdominal ganglia (VI-VIII) form complex in segments V and VI (Fig. 28). Abdominal segments $I X-X$ (Figs. 2, 15, 28 and 29). 
Segment IX well developed, slightly narrower and longer than VIII. Tergum with articulated, one-segmented, apically pointed urogomphgi. Segment X represented by elongate, slightly curved and cone-shaped pygopod (Fig. 2) with two apical hooks. Chaetotaxy: Segment IX with seven setae (93, 95-97, 99, 100 and 101) and two pores (pore 'm' like in other segments and new pore 'o'); urogomphi with six setae (130-135) and one pore (p); pygopod with four setae (136139) and two pores (q, r). Musculature (Fig. 29; not treated by Kéler, 1923): Dorsal muscles: M. dorsalis abdominis a, retractor of segment X (Fig. 29: rX), O: laterally on penultimate phragma, I: posterior margin of segment X. M. dorsalis abdominis b, retractor of urogomphus (Fig. 29: rug), O: mesally on penultimate phragma, I: anterior margin of urogomphus. M. dorsalis abdominis c, protractor of urogomphus (Fig. 29: pug), O: upper hind margin of segment X, I: posterior margin of urogomphus. Ventral muscles: $\mathrm{M}$. ventralis abdominis, $\mathrm{O}$ : ventromesally on low fold separating segment VIII and IX, I: ventrally on low fold separating segment IX and X.

Spiracles (Fig. 3). Circular annular (= uniformous) spiracles present on mesothorax. Abdominal segments without spiracles.

Postcephalic gut (Figs. 26 and 28). Oesophagus approximately round in cross-section, with thin intima and thin layer of ring muscles (Fig. 26). Wide and thin-walled crop connects oesophagus with mid-gut at posterior mesothoracic margin. Mid-gut cells moderately high. Anterior part (approximately $35 \mu \mathrm{m}$ long) internally lined with thick layer of substance resembling cuticle, possibly representing a specific kind of peritrophic membrane. Similar layer present at posterior mid-gut region. Posterior margin of mid-gut marked by origin of malpighian tubules. Hind-gut star-shaped in cross-section, with narrow dorsolateral, lateral and ventrolateral folds and ring muscle layer. Loop separates anterior hind-gut (or ileocolon) from rectal part (Fig. 28); rectal part with six rectal papillae.

Malpighian tubules (Fig. 28). Four free malpighian tubules; one pair directed posteriorly, the other pair directed anteriorly after a short posterior loop.

\section{Discussion}

\subsection{Miniaturisation}

The complexity of chaetotaxy, head musculature, tentorium, cervical muscles, and digestive tract is apparently not affected by the very small size of the larvae of Ptinella. This is also the case in minute larvae of the myxophagan families Hydroscaphidae and Sphaeriusidae ${ }^{1}$ (Beutel and Haas, 1998; Beutel et al., 1999) and, in respect to chaetotaxy, in Typhlocharis, Geocharidius and other Bembidiini (Carabidae, see: Arndt et al., 1999; Grebennikov

\footnotetext{
${ }^{1}$ Formerly Microsporidae.
}

and Maddison, 2000; Grebennikov, 2002). However, several characteristics are probably correlated with miniaturisation. In contrast to larvae of Hydroscapha (and most other groups of beetles) (Beutel, 1993, 1995, 1996, 1999; Beutel and Pollock, 2000) the frontal arms and epicranial stem are absent (also absent in Sphaeriusidae; Beutel et al., 1999). The molar structure is simplified compared to other staphylinoid larvae (e.g. Newton, 1991). The lacinia is absent or fused with the galea (also in all larvae of Myxophaga). The mentum and submentum are indistinctly separated and the gular area is not well defined. No well defined sclerites are recognizable on the body segments. The musculature of the thorax and abdomen is simplified compared to other larvae. Only one furco- or sterno-coxal muscle is present in thoracic segments of larval Ptinella, whereas four are present in the larva of Dytiscus marginalis Linnaeus (see: Speyer, 1922), and three in Oryctes nasicornis (Linnaeus) (see: Crome, 1957: Fig. 36). Only dorsal and ventral longitudinal muscles and two bundles of dorsoventral muscles could be identified in the abdominal segments I-VIII (Figs. 28 and 29). A distinctly more complex abdominal muscle system is found in larger larvae of other families (Speyer, 1922; Jösting, 1942; Crome, 1957). Another result of miniaturisation is the absence of abdominal spiracles. This is also the case in Collembola and Protura (e.g. Beutel and Gorb, 2001). Abdominal spiracles are present but transformed into spiracular gills in larvae of Myxophaga (e.g. Beutel et al., 1999). Another possible result of miniaturisation is the presence of numerous small round structures similar to cerebral cell bodies between the muscle fibres (Figs. 21-25). A similar condition is present in adults and larvae of Sphaeriusidae (pers. obs. Beutel). It is likely to assume that these structures are the external nuclei of muscles with a surrounding cytoplasmatic layer. The connection with muscles is still recognizable in adults and larvae of Microsporus, but not in semi-thin microtome sections of larvae of Ptinella. Another likely effect of miniaturisation is the elongate shape of the cerebrum reaching the mesothorax posteriorly (Fig. 26). A similar shape and position of the brain is found in the minute larvae of Microsporus (see: Beutel and Haas, 1998) and the caraboid larvae of Micromalthus (Beutel and Hörnschemeyer, 2002). A negative allometry between the size of head capsule and cerebrum seems to be a general feature of Coleoptera (Beutel and Haas, 1998). Interestingly the second effect, i.e. the dislocation of protocerebral parts to the thorax, is not found in adults examined (e.g. Sphaeriusidae; Zoraptera; pers. obs. Beutel). The more distinct constriction of the cervical region and the higher mobility apparently are not compatible with this option. However, parts of the brain appear as being squeezed very tightly into interspaces between other structures in very small adults. A further unusual condition likely to be related with small size is the abnormally large relative size of the cell bodies of the neurones (Figs. 21 and 26). It was pointed out by Beutel and Haas (1998), that a lower limit of the size of neurones is 
probably reached in beetle larvae of myxophagan size ( $2 \mathrm{~mm}$ and less), and this is confirmed by the results of this study.

\subsection{Mouthparts and feeding habits}

The structure and configuration of the mouthparts is similar to what is found in other fungivorous (or algophagus) larvae. Mandibles with slender apical parts, a prostheca and an asperate mola, and maxillae with brushlike apical structures seem to be characteristic for larvae with a preference for fungal hyphae or spores. An almost vertical labrum, which fits closely with the upper side of the mandibles (Figs. 6 and 7), is not only found in larvae of Ptinella, but also in larvae of Sepedophilus Gistel, 1856 (Leschen and Beutel, 2001) and Sphindus (Beutel and Ślipinśki, 2001). This condition is correlated with the formation of a preoral chamber in the larvae of the latter two taxa.

\subsection{Phylogeny}

Several unusual features are shared by ptiliid larvae and larvae of other staphylinoid families. Fimbriate galeae are a possible synapomorphy of Ptiliidae (Figs. 5 and 16; not detectable in spore-tube genera; Dybas, 1976: figs. 3(c), 8(b) and 21(b)), Hydraenidae (absent in known larvae of Ochthebius; Beier and Pomeisl, 1959; Beutel and Molenda, 1997), Agyrtidae (apical fringe of 2-5 rows of hair; Newton, 1991) and Leiodidae. The presence of a digitiform appendage at the base of the ultimate maxillary palpomere seems to be another characteristic feature of the larvae of these families (e.g. Dybas, 1976). However, this character has to be examined in more taxa.

The presence of a complex apical appendage on the distal maxillary palpomere (Dybas, 1976; Beutel and Molenda, 1997), and of hooks on abdominal segment $X$ are presumably derived features shared by larvae of Ptiliidae and Hydraenidae (e.g. Delgado and Soler, 1996, 1997; Hansen, 1997). Similar hooks have probably evolved independently in larvae of Sphaeriusidae (three pairs; Beutel et al., 1999) and Gyrinidae (two pairs; Lawrence, 1982).

Some other features found in larvae of Ptinella may turn out as useful for a phylogenetic placement of Ptiliidae, when more information on other larvae is available. The postcephalic digestive tract is characterized by the presence of a thick internal sclerotized layer in the anterior and posterior mid-gut (Figs. 26 and 28), which may represent a modified peritrophic membrane. A loop with a distinct ring muscle layer is present between the anterior and posterior hind-gut (Fig. 28). A similar condition was described for wood boring larvae of Cerambycidae (Švácha et al., 1997) and Micromalthidae (Beutel and Hörnschemeyer, 2001). The Malpighian tubules are arranged in a specific manner, with two directed anteriorly and two directed posteriorly.
The monophyly of Ptiliidae is well founded by derived larval (and adult) character states. Several features found in larvae of Ptinella are presumptive autapomorphies of the family: presence of a distinct setiferous protuberance close to the mandibular base (Fig. 5; Dybas, 1976: figs. 2(b) and 8(b)), absence of head sutures (Figs. 4 and 5; Dybas, 1976, 1991), and absence of a well defined lacinia. Another possibly derived feature of Ptiliidae is the absence of subantennal glands, which were not identified in larvae of Ptinella, but are present in all other staphylinoid larvae examined (incl. Hydraenidae; Beutel and Molenda, 1997). The almost straight and vertical structures formed by the posterior and dorsal tentorial arms and the almost vertical orientation of $\mathrm{Mm}$. tentoriocardinalis and -stipitalis are other potential autapomorphies.

A feature, which distinguishes larvae of Ptinella and other ptiliid genera from larvae of Nossidium is the absence of all abdominal spiracles and the complete absence of eyes. Larvae of Nossidium possess spiracles on the abdominal segments I-VIII and a pair of distinct eyespots (Dybas, 1976: fig. 6(a)). The presumably derived character states may be considered as apomorphies of a ptiliid subgroup, which does not include Nossidium, whereas the absence of well defined stemmata is probably an autapomorphy of the whole family.

Some notable differences in external features between the larva of $P$. tenella described here and the ptiliid larvae already known (for references see Section 1) should be emphasized. We found no dome-like sensilla near the sensorium on the second antennomere. The labrum is completeley fused with the anterior margin of the head capsule, correlated with the loss of M. frontoepipharyngalis. At least a fine suture is present in other known ptiliid larvae (Dybas, 1976, 1991). Furthermore we could not find a group of three short setae normally located on each side on the dorsal surface of the cranium near the occipital foramen. The setae are probably homologous to setae P2-P4 in aleocharine larvae (Ashe and Watrous, 1984: fig. 4) and setae PA1-PA3 in carabid larvae (Bousquet and Goulet, 1984: fig. 1). They are possibly responsible for sensation of cephalic retraction into the prothorax. It is plausible to assume, that the loss or the reduction to an unrecognizable size is correlated with the highly protracted head of Ptinella.

\section{Conclusions}

A conspicuos effect of very small size is the very large relative size of the cerebrum and a shift of large parts to the pro- and mesothorax. However, the overall complexity of the head is not effected by the miniaturization. Normal function of antennae and mouthparts apparently require a fully developed tentorium and muscle system in staphylinoid larvae. Simplifications are moderate and include slight modifications of the mouthparts and fusion or indistinct separation of sclerites. In contrast to that, apparently the 
requirements of a functional thoracic locomotor system can be fulfilled with a distinct reduction of sclerites and muscles in larvae of Ptinella. The abdomen plays a minor role in locomotion at best, and the highest degree of reduction of the musculature (and tracheal system) is found in this tagma.

The morphological results support monophyletic groups comprising Ptiliidae + Hydraenidae + Agyrtidae + Leiodidae, Ptiliidae + Hydraenidae, Ptiliidae, and Ptiliidae excl. Nossidium. A close relationship between Ptiliidae and Hydraenidae is in contrast to Beutel (1994) but in agreement with Lawrence and Newton (1982) and Hansen (1997). Staphylinoid affinities of Hydraenidae are also clearly supported by recent molecular investigations (16S rDNA; Korte et al. (2002)).

\section{Acknowledgments}

Shaun A. Forgie (Pretoria, South Africa), Margaret K. Thayer, and Alfred F. Newton, Jr. (both Chicago, USA) critically read the MS; the latter person and Mikael Sörensson (Lund, Sweden) identified the species of Ptinella. Stanislav Gorb (Tübingen, Germany) made SEM pictures of the larvae. W. Eugene Hall (Lincoln, USA) read the MS and helped with author's names for some ptiliid species. This work was supported by the DFG (project BE1789/2-1), which is gratefully acknowledged.

\section{References}

Arndt, E., Grebennikov, V.V., Zaballos, J.M.P., 1999. Description of the larvae of a representative of Anillina with a key to the Palaearctic genera of Bembidiini (Coleoptera: Carabidae). Koleopterologische Rundschau 69, 11-17.

Ashe, J.S., Watrous, L.E., 1984. Larval chaetotaxy of Aleocharinae (Staphylinoidea) based on a description of Atheta coriarica Kraatz. The Coleopterists Bulletin 38 (2), 165-179.

Beier, M., Pomeisl, E., 1959. Einiges über Körperbau und Lebensweise von Ochthebius exsculptus Germ. und seiner Larve (Col. Hydroph. Hydraen.). Zeitschrift für Morphologie und Ökologie der Tiere 48, $72-88$.

Beutel, R.G., 1993. Phylogenetic analysis of Adephaga (Coleoptera) based on characters of the larval head. Systematic Entomology 18, 127-147.

Beutel, R.G., 1994. Phylogenetic analysis of Hydrophiloidea (Coleoptera: Polyphaga: Staphyliniformia) based on characters of the head of adults and larvae. Koleopterologische Rundschau 64, 103-131.

Beutel, R.G., 1995. Phylogenetic analysis of Elateriformia (Coleoptera: Polyphaga) based on larval characters. Journal of Zoological Systematics and Evolutionary Research 33, 145-171.

Beutel, R.G., 1996. Study of the larva of Nosodendron fasciculare (Olivier 1790) (Coleoptera: Nosodendridae) with implications to the phylogeny of Bostrichiformia. Journal of Zoological Systematics and Evolutionary Research 34, 121-134.

Beutel, R.G., 1999. Morphology and evolution of the larval head structures of Hydrophiloidea and Histeroidea (Coeloptera: Staphylinidae). Tijdschrift voor Entomologie 142, 9-30.

Beutel, R.G., Gorb, S., 2001. Ultrastructure of attachment specializations of hexapods (Arthropoda): evolutionary patterns inferred from a revised ordinal phylogeny. Journal of Zoological Systematics and Evolutionary Research 39, 177-207.

Beutel, R.G., Haas, A., 1998. Larval head morphology of Hydroscapha natans LeConte 1874 (Coleoptera, Myxophaga, Hydroscaphidae) with special reference to miniaturization. Zoomorphology 18, 103-116.

Beutel, R.G., Hörnschemeyer, T., 2002. Larval morphology and phylogenetic position of Micromalthus debilis LeConte (Coleoptera: Micromalthidae). Systematic Entomology 27, 169-190.

Beutel, R.G., Molenda, R., 1997. Comparative morphological study of larvae of Staphylinoidea (Coleoptera Polyphaga) with phylogenetic implications. Zoologischer Anzeiger 236, 37-67.

Beutel, R.G., Pollock, D.A., 2000. Larval head morphology of Phycosecis litoralis (Pascoe) (Coleoptera Phycosecidae) with phylogenetic implications. Invertebrate Taxonomy 14, 825-835.

Beutel, R.G., Ślipinśki, S.A., 2002. Comparative study of larval head structures of Sphindidae and Protocucujidae (Cucujoidea, Coleoptera). European Journal of Entomology 99 in press.

Beutel, R.G., Maddison, D.R., Haas, A., 1999. Phylogenetic analysis of Myxophaga (Coleoptera) using larval characters. Systematic Entomology 24, 1-23.

Bousquet, Y., Goulet, H., 1984. Notation of primary setae and pores on larvae of Carabidae (Coleoptera: Adephaga). Canadian Journal of Zoology 62, 573-588.

Böving, A.G., Craighead, F.C., 1931. An illustrated synopsis of the principal larval forms of the order Coleoptera. Entomologica Americana (N.S.) 54, 1-351.

Costa, C., Vanin, S.A., Casari-Chen, S.A., 1988. Larvas de Coleoptera do Brasil. Museu de Zoologia, Universidade de São Paulo, São Paulo. 282 pp. +165 plates.

Crome, W., 1957. Zur Morphologie und Anatomie der Larve von Oryctes nasicornis L. (Coleoptera: Dynastidae). Deutsche Entomologische Zeitschrift (N.F.) 4, 228-262.

Delgado, J.A., Soler, A.G., 1996. Morphology and chaetotaxy of the firstinstar larva of Hydraena (Phothydraena) hernandoi Fresneda \& Lagar (Coleoptera: Hydraenidae). Koleopterologische Rundschau 66, $147-154$.

Delgado, J.A., Soler, A.G., 1997. Morphology and chaetotaxy of larval Hydraenidae (Coleoptera) I: genus Limnebius Leach, 1815 based on a description of Limnebius cordobanus d'Orchymont. Aquatic Insects 19 (1), 37-49.

Dybas, H.S., 1976. The larval characters of featherwing and limulodid beetles and their family relationships in the Staphylinoidea (Coleoptera: Ptiliidae and Limulodidae). Fieldiana: Zoology 70 (3), 29-78.

Dybas, H.S., 1991. Family Ptiliidae. In: Stehr, F.W., (Ed.), Immature Insects, vol. 2. Kendall/Hunt Publishers, Dubuque, Iowa, pp. 144-658.

Grebennikov, V.V., Maddison, D.R., 2000. Larvae of Bembidiini (Coleoptera: Carabidae): subtribes Tachyina and Xystosomina. European Journal of Entomology 97, 223-240.

Grebennikov, V.V., 2001. Cymbionotum larvae are still unknown (Coleoptera: Carabidae): a case of larval misidentification. The Coleopterists Bulletin 55 (1), 50.

Grebennikov, V.V., 2002. Description of first-instar Geocharidius Jeannel larva (Coleoptera: Carabidae: Trechitae) with a discussion on the phylogeny of Anillina. European Journal of Entomology 99 in press.

Hall, W.E., 1999. Generic revision of the tribe Nanosellini (Coleoptera: Ptiliidae: Ptiliinae). Transactions of the American Entomological Society 125 (1-2), 39-126.

Hansen, M., 1997. Phylogeny and classification of the staphyliniform beetle families (Coleoptera). Biologiske Skrifter 48, Det Kongelige Danske Videnskabernes Selskab, Munksgaard, Copenhagen, 339 p.

Hinton, H.E., 1941. The immature stages of Acrotrichis fascicularis (Herbst) (Coleoptera: Ptiliidae). Entomologists Monthly Magazine 77, $245-250$.

Jösting, E.A., 1942. Die Innervierung des Skelettmuskelsystems des Mehlwurms (Tenebrio molitor L., Larve). Zoologische Jahrbücher Abteilung für Anatomie und Ontogenie der Tiere 67, 381-460. 
Kéler, S.V., 1963. Entomologisches Wörterbuch, Akademie Verlag, Berlin, 744 pp. + plates I-XXXIII.

Kilian, A., Burakowski, B., 2000. A description of the late-instar larva of Nossidium pilosellum (Marsham, 1802) (Coleoptera: Ptiliidae). Genus 11 (4), 527-539.

Korte, A., Bernhard, D., Beutel, R., 2002. Molecular evidence for a systematic placement of Hydraenidae and Histeroidea (Coleoptera, Staphyliniformia). Short communications of the 95. Annual Meeting of the Deutsche Zoologische Gesellschaft (DZG) in Halle, in press.

Kovarik, P.W., Passoa, S., 1993. Chaetotaxy of larval Histeridae (Coleoptera: Hydrophiloidea) based on a description of Onthophilus nodatus LeConte. Annals of Entomological Society of America 86 (5), $560-576$.

Larsén, O., 1966. On the morphology and function of locomotor organs of the Gyrinidae and other Coleoptera. Opuscula Entomologica Supplementum 30, 1-241.

Lawrence, J.F., 1982. Coleoptera. In: Parker, S., (Ed.), Synopsis and Classification of Living Organisms, McGraw-Hill, New York, pp. $482-553$

Lawrence, J.F., Newton, A.F., 1982. Evolution and classification of beetles. Annual Review of Ecology and Systematics 13, 261-290.

Lawrence, J.F., 1991. Order Coleoptera (general discussion, family key, various family treatments). In: Stehr, F.W., (Ed.), Immature Insects, vol. 2. Kendall/Hunt Publishers, Dubuque, Iowa, pp. 144-658.

Leschen, R.A.B., Beutel, R.G., 2002. Pseudotracheal tubes, larval head, and mycophagy in Sepedophilus (Coleoptera: Staphylinidae: Tachyporinae). Journal of Zoological Systematics and Evolutionary Research 39, 25-35.

Newton, A.F. Jr., 1991. Agyrtidae (Staphylinoidea). In: Stehr, F.W., (Ed.), Immature Insects, vol. 2. Kendall/Hunt Publishers, Dubuque, Iowa, pp. $324-326$

Paulian, R., 1941. Les premiers états des Staphylinoidea (Coleoptera). Étude de morphologie comparée. Mémoires du Museum National d'Histoire Naturelle (N.S.) 15, 1-361.

Sörensson, M., 1997. Morphological and taxonomical novelties in the world's smallest beetles, and the first old world record of Nanosellini (Coleoptera: Ptiliidae). Systematic Entomology 22, 257-283.

Speyer, W., 1922. Die Muskulatur der Larve von Dytiscus marginalis L. Ein Beitrag zur Kenntnis des Insektenkörpers. Zeitschrift für Wissenschaftliche Zoologie 119, 423-492.

Švácha, P., Wang, J.-J., Chen, Sh.-Ch., 1997. Larval morphology and biology of Philus antennatus and Heterophilus punctulatus, and systematic position of the Philinae (Coleoptera: Cerambycidae and Vesperidae). Annales de la Société Entomologique de France, N.S. 33 (3), 323-369. 